\title{
Pediatric abusive head trauma and stroke
}

\author{
Nickalus R. Khan, MD, ${ }^{1}$ Brittany D. Fraser, MS, ${ }^{2}$ Vincent Nguyen, MD, ${ }^{1}$ Kenneth Moore, MD, ${ }^{1}$ \\ Scott Boop, MPH, ${ }^{3}$ Brandy N. Vaughn, RN, ${ }^{4}$ and Paul Klimo Jr., MD, MPH ${ }^{1,4,5}$
}

1Department of Neurosurgery and ${ }^{2}$ College of Medicine, University of Tennessee Health Science Center, Memphis, Tennessee; ${ }^{3}$ University of Arkansas for Medical Sciences, College of Medicine, Little Rock, Arkansas; ${ }^{4}$ Department of Neurosurgery, Le Bonheur Children's Hospital; and ${ }^{5}$ Semmes Murphey Clinic, Memphis, Tennessee

\begin{abstract}
OBJECTIVE Despite established risk factors, abusive head trauma (AHT) continues to plague our communities. Cerebrovascular accident (CVA), depicted as areas of hypodensity on CT scans or diffusion restriction on MR images, is a well-known consequence of AHT, but its etiology remains elusive. The authors hypothesize that a CVA, in isolation or in conjunction with other intracranial injuries, compounds the severity of a child's injury, which in turn leads to greater health care utilization, including surgical services, and an increased risk of death.
\end{abstract}

METHODS The authors conducted a retrospective observational study to evaluate data obtained in all children with AHT who presented to Le Bonheur Children's Hospital (LBCH) from January 2009 through August 2016. Demographic, hospital course, radiological, cost, and readmission information was collected. Children with one or more CVA were compared with those without a CVA.

RESULTS The authors identified 282 children with AHT, of whom $79(28 \%)$ had one or more CVA. Compared with individuals without a CVA, children with a stroke were of similar overall age (6 months), sex (61\% male), and race $(56 \%$ African-American) and had similar insurance status (81\% public). Just under half of all children with a stroke (38/79, 48\%) were between 1-6 months of age. Thirty-five stroke patients (44\%) had a Grade II injury, and $44(56 \%)$ had a Grade III injury. The majority of stroke cases were bilateral (78\%), multifocal (85\%), associated with an overlying subdural hematoma $(86 \%)$, and were watershed/hypoperfusion in morphology (73\%). Thirty-six children (46\%) had a hemispheric stroke. There were a total of 48 neurosurgical procedures performed on 28 stroke patients. Overall median hospital length of stay (11 vs 3 days), total hospital charges ( $\$ 13.8$ vs $\$ 6.6$ million), and mean charges per patient ( $\$ 174,700$ vs $\$ 32,500)$ were significantly higher in the stroke cohort as a whole, as well as by injury grade (II and III). Twenty children in the stroke cohort (25\%) died as a direct result of their AHT, whereas only 2 children in the nonstroke cohort died (1\%). There was a $30 \%$ readmission rate within the first 180 -day postinjury period for patients in the stroke cohort, and of these, approximately $50 \%$ required additional neurosurgical intervention(s).

CONCLUSIONS One or more strokes in a child with AHT indicate a particularly severe injury. These children have longer hospital stays, greater hospital charges, and a greater likelihood of needing a neurosurgical intervention (i.e., bedside procedure or surgery). Stroke is such an important predictor of health care utilization and outcome that it warrants a subcategory for both Grade II and Grade III injuries. It should be noted that the word "stroke" or "CVA" should not automatically imply arterial compromise in this population.

https://thejns.org/doi/abs/10.3171/2017.4.PEDS16650

KEY WORDS pediatric abusive head injury; nonaccidental trauma; stroke; subdural hematoma; hemispheric; cerebrovascular accident

$\mathrm{P}$ EDIATRIC abusive head trauma (AHT) is the third most common cause of head injury in children-following falls and motor vehicle crashes-and is the most common cause of serious head injury before the age of 1 year. ${ }^{6,12}$ The Centers for Disease Control and Preven- tion has defined AHT as an injury to the skull/intracranial contents of an infant/young child aged 5 years or fewer due to intentional abrupt impact and/or violent shaking. ${ }^{37}$ Injuries include skull fractures, cerebral contusions and hemorrhage in any compartment-epidural, subarachnoid,

ABBREVIATIONS ACA = anterior cerebral artery; $A D C=$ apparent diffusion coefficient; $A H T=$ abusive head trauma; $A I C A=$ anterior inferior cerebellar artery; CARES = Neurosurgery and the Child Advocacy Resource and Evaluation Services; CVA = cerebrovascular accident; DWI = diffusion-weighted imaging; LBCH = Le Bonheur Children's Hospital; LOS = length of stay; MCA = middle cerebral artery; NAT = nonaccidental trauma; PCA = posterior cerebral artery; PICA = posterior inferior cerebellar artery; SCA = superior cerebellar artery.

SUBMITTED November 23, 2016. ACCEPTED April 3, 2017.

INCLUDE WHEN CITING Published online June 2, 2017; DOI: 10.3171/2017.4.PEDS16650. 
intraventricular, and subdural. The mechanism of injury is thought to be due to the sudden angular deceleration experienced by the brain and cerebral vessels, not the specific contact forces applied to the surface of the head. Thus, the term "shaken-impact syndrome" is more fitting than the more common "shaken-baby syndrome." 16

AHT is generally thought to be precipitated by inconsolable crying, with victims being more commonly male and from socioeconomically depressed families. ${ }^{10,34,35,37}$ Neurological morbidity and mortality rates are, in general, worse than those of accidental trauma; the mortality rate for AHT is $10 \%-20 \%$ or greater, and half to twothirds of surviving patients have moderate to severe neurological deficits or sequelae, including motor, vision, behavioral, communication, and epilepsy. 4,13,15,17,26,31 This has created a woefully underrecognized public health calamity given the high initial and long-term costs for medical and ancillary services, coupled with many years of lost productivity.

The many types of intracranial injuries inflicted on children with AHT can be detected with CT and MRI, each of which has advantages and disadvantages. , $^{1,3,9,19,20,28,42}$ MRI is superior to CT at detecting traumatic intraparenchymal injuries. ${ }^{9}$ There are number of imaging findings that are more common in children with abusive injury rather than accidental injuries. These include subdural hematomas of different ages (acute, subacute, and chronic) or mixed with subarachnoid CSF or in certain locations such as the posterior fossa or interhemispheric space; brain lacerations; retroclival, epidural, or subdural hematomas; cortical vein thrombosis; and a high association with cervical ligamentous injury. ${ }^{11,25,27,29,30,36,43,46}$

Another injury that is more prevalent in children with AHT is a cerebrovascular accident (CVA). ${ }^{24,30}$ During the era in which CT was the predominant imaging technology, brain infarction was diagnosed as areas of hypodensitythe most extreme form being unilateral or bilateral panhemispheric hypodensity, typically underlying a SDHand was given the rather grim description of "big black brain." ${ }^{14}$ In their 1984 publication, Merten et al. found that the most common cerebral lesion in children with AHT was unilateral or bilateral diffuse cerebral edema, half of the cases being associated with an extracerebral hemorrhagic collection..$^{33}$ Focal cerebral infarctions were also present, but less common. With MRI, these areas of hypodensity shown on CT are seen as infarctions, with resulting cytotoxic edema seen best on diffusion-weighted imaging (DWI) and apparent diffusion coefficient (ADC) maps. Numerous publications have shown that number and volume of DWI/ADC-positive lesions, in both accidental and nonaccidental trauma, correlate with early and late neurological outcomes. . $, 5,7,22,39,41,44,45$

We recently published our 6-year experience with AHT and introduced a novel injury grading scale. ${ }^{8}$ Using our AHT database, we sought to identify all patients who sustained a CVA, either using CT or MRI to and combine a detailed radiological analysis with demographic, clinical, cost, and readmission data. We postulate that an AHT-related CVA predicts a more severe injury, which translates to a greater likelihood of needing surgical intervention, longer hospital stay, and greater cost.

\section{Methods}

\section{Database Creation, Variables, and Definitions}

The University of Tennessee Institutional Review Board approved this study. Le Bonheur Children's Hospital (LBCH) is a 255-bed children's hospital located in downtown Memphis that serves a 200-mile radius for an estimated 1.4 million Mid-South children from 5 states: Tennessee, Mississippi, Arkansas, Kentucky, and Missouri. Neurosurgery and the Child Advocacy Resource and Evaluation Services (CARES) team-as well as other services as needed, such as trauma or general pediatrics-independently evaluated all children with suspected AHT. AHT, or nonaccidental trauma (NAT), was defined as skull fracture or intracranial hemorrhage in a child under the age of 5 years with a suspicious mechanism, or direct evidence of other intentional injuries or consequences from such actions (e.g., retinal hemorrhages, old or new fractures, burns, or other soft tissue injury) that was consistent with AHT, according to the final assessment of the CARES team.

Our initial AHT database was created by identifying cases through one of two sources: a prospective trauma service database of pediatric traumatic injuries (intentional and unintentional), and an electronic medical record search to identify children with joint consultations from neurosurgery and CARES. This identified cases from 2009 to 2014. Since 2014, we have added cases as they present to our service. Thus, we believe that our database contains the vast majority of AHT cases evaluated at LBCH since 2009. The time period for data collection was January 2009 thru August 2016.

For each patient, we have records of demographic information (e.g., age, sex, race, and date of injury), hospital course (e.g., extent and grade of injury, need for any neurosurgical intervention, length of hospital stay, and in-hospital mortality), and charges associated with the initial hospitalization. Hospital "charges" were considered a surrogate for "cost," although technically "charges" are always greater than "costs," typically by a fixed factor (professional fees are not included). ${ }^{18}$ Injury severity was graded as follows: Grade I, skull fracture alone with or without associated craniofacial soft-tissue injury; Grade II, intracranial hemorrhage or cerebral edema not requiring neurosurgical intervention or bedside procedure; and Grade III, intracranial hemorrhage requiring neurosurgical intervention or resulting in death as a direct result of AHT.

Using our AHT database, we first reviewed the imaging reports of all children to identify those with a definite or suspected a CVA. The diagnosis of CVA or a strokelike finding is well established on MRI as an area of brain parenchyma that is hyperintense on DWI and correspondingly hypointense on the ADC map. For those cases in which CT was the only imaging modality, a stroke was diagnosed as a hypodense region that was not considered to be consistent with a contusion or a response to an intraparenchymal hemorrhage (i.e., noninfarct-related cerebral edema) - in an arterial, watershed, or venous distribution-and present (and typically more hypodense) on follow-up imaging. All images for each confirmed AHT case with stroke were reviewed in detail along with the dictated 
report (authored by one of two fellowship-trained pediatric neuroradiologists) with the following information abstracted: 1) date of CVA; 2) imaging modality used to make diagnosis; 3) location: cerebrum, cerebellum, basal ganglia and thalamus, or brainstem; 4) morphology: arterial, venous or watershed/hypoperfusion, including wellknown perfusion sensitive areas, such as layers 3, 5, and 6 of the cerebral cortex (laminar necrosis), basal ganglia, cerebellum, and hippocampi (CA1 and CA 3 regions); 5) vascular territory: middle cerebral artery (MCA), anterior cerebral artery (ACA), posterior cerebral artery (PCA), posterior inferior cerebellar artery (PICA), anterior inferior cerebellar artery (AICA), and superior cerebellar artery (SCA); 6) number of vascular distributions affected; 7) laterality: unilateral or bilateral; 8) number of strokes: focal or multifocal; 9) presence of a hemispheric stroke, defined as a stroke that involves all or nearly the entire hemisphere, involving MCA, ACA, and PCA territories; and 10) presence of subdural hematoma overlying a stroke.

To clarify, a holohemispheric stroke would be recorded as having 3 vascular distributions (MCA, ACA, and PCA) and a watershed stroke would be recorded as having 2 vascular distributions with the exact vascular territory dependent on location (e.g., MCA-PCA). Images were reviewed with a neuroradiologist, if there were any questions or discrepancy between the report and the images or between studies. If a patient had both MRI and CT scans, then we generally used the former for data collection given the greater detail afforded by MRI.

We also recorded whether children with NAT-induced CVA were readmitted within 180 days of their original admission, the reason for their readmission, and whether they underwent any neurosurgical procedure during this readmission.

\section{Study Hypothesis and Questions}

We hypothesize that the development of a stroke as a result of intentional trauma to a child, in isolation or with other intracranial injury, worsens that child's overall injury severity, leading to longer hospital stay, greater risk of needing surgical services, higher health care utilization, and an increased risk of death. With this retrospective observational study, we posed the following questions: What are the demographic and clinical characteristics of AHT cases with associated stroke? What are the characteristics of the strokes? How do abused children with a stroke differ from those without a stroke in terms of need for neurosurgery, length of stay, and financial impact (i.e., hospital charges)? What are predictors of mortality? What percentage of abused children with a stroke needs to be readmitted within the first 6-months of their injury, what percentage needs neurosurgical intervention, and what are their associated hospital charges?

\section{Statistical Analysis}

Patient demographic, clinical, and radiographic characteristics were summarized using median (range) and proportions for continuous and categorical data, respectively. Among those children with a stroke, a linear logis- tic regression analysis was performed in an effort to determine factors that were predictive of mortality. Variables included in the model were sex, age (kept as a continuous variable), stroke laterality (unilateral or bilateral), stroke number (focal or multifocal), and presence or absence of hemispheric stroke. All statistical analysis was performed using Microsoft Excel and SPSS version 22 (IBM).

\section{Results \\ Demographics}

From January 2009 thru August 2016, a total of 282 children with AHT were identified; 79 were diagnosed with one or more CVA (28\%). Table 1 shows the demographics for the 2 subgroups and the entire patient population. The majority of patients in both cohorts were African American, male, and publically insured. Children less than 1 month of age had the least at risk for strokes ( 3 of 79 [4\%]), whereas those 1-6 months had the greatest risk (38 of 79 [48\%]).

\section{Hospital Course, Cost, and Readmission}

Table 2 contains information on grade of injury, length of stay (LOS) (overall and by injury grade), and cost (overall and by injury grade). The stroke cohort had proportionately fewer patients with Grade II injuries (44\% vs 52\%), but more patients with Grade III injuries (56\% vs $13 \%$ ), of whom $28(35 \%)$ had an intracranial hemorrhage or edema that required surgery or a procedure, and $20(25 \%)$ died as a direct result of their AHT. Only 2 children in the nonstroke cohort died (1\%).

The median LOS was 11 days (range 0-80 days) for those children with a stroke, compared with 3 days (range 1-36 days) for those without. The total LOS for all patients was 1295 days. The median cost (i.e., hospital charges) was $\$ 117,000$ (range $\$ 9980-\$ 882,000$ ) for the stroke group, compared with $\$ 19,900$ (range $\$ 3700-\$ 313,000$ ) for the nonstroke patients. Figure 1 graphically shows this disparity in hospital charges with a box-and-whisker diagram. The total hospital charges associated with the first admission were $\$ 13.8$ million for the stroke cohort and \$20.4 million for all 282 children.

A summary of surgical procedures performed on the Grade III stroke patients is presented in Table 3. The most common procedures were intracranial pressure (ICP) monitor placement $(\mathrm{n}=14)$, decompressive craniectomy $(n=12)$, and bur hole evacuation of a subdural hemorrhage $(\mathrm{SDH}, \mathrm{n}=8)$.

Within the first 6 months of being discharged, 24 stroke patients were readmitted (30\%), 15 of whom were readmitted for neurosurgical issues. Thirteen patients (54\%) required a return to the operating room: 5 for cranioplasty and 4 for shunts (all de novo: 3 bilateral subduroperitoneal shunts and 1 ventriculoperitoneal shunt), 3 for craniotomies ( 2 for evacuation of a subdural abscess and 1 for a loculated chronic SDH), and 1 bur hole evacuation of a subdural collection (Table 4). The 2 neurosurgical admissions not requiring surgical intervention were for a cerebral angiogram and for a subdural collection that eventually resolved on its own. For the 15 neurosurgical readmissions, the total cost was $\$ 697,000$ (median $\$ 41,000$ ). 
TABLE 1. Demographics of 282 children with AHT

\begin{tabular}{|c|c|c|c|}
\hline \multirow[b]{2}{*}{ Variable } & \multicolumn{2}{|c|}{ No. of Patients (\%) } & \multirow[b]{2}{*}{ Total (\%) } \\
\hline & Without CVA & With CVA & \\
\hline No. of patients & 203 & 79 & 282 \\
\hline \multicolumn{4}{|l|}{ Race } \\
\hline White & $81(40)$ & $29(37)$ & $110(39)$ \\
\hline African American & $108(53)$ & $44(55)$ & $152(54)$ \\
\hline Other & $14(7)$ & $6(8)$ & $20(7)$ \\
\hline \multicolumn{4}{|l|}{ Sex } \\
\hline Male & $122(60)$ & $48(61)$ & $170(60)$ \\
\hline Female & $81(40)$ & $31(39)$ & $112(40)$ \\
\hline \multicolumn{4}{|l|}{ Age (yrs) } \\
\hline Overall median (range) & $0.54(0.03-6.47)$ & $0.48(0.06-6.93)$ & $0.52(0.03-6.93)$ \\
\hline$<1 \mathrm{mos}$ & $12(6)$ & $3(4)$ & $15(5)$ \\
\hline $1-6$ mos & $96(47)$ & $38(48)$ & $134(48)$ \\
\hline $7-12$ mos & $51(25)$ & $11(14)$ & $62(22)$ \\
\hline $13-24$ mos & $22(11)$ & $11(14)$ & $33(12)$ \\
\hline 24 mos- 5 yrs & $22(11)$ & $16(20)$ & $38(13)$ \\
\hline \multicolumn{4}{|l|}{ Insurance status } \\
\hline Private & $21(10)$ & $10(13)$ & $31(11)$ \\
\hline Public & $171(84)$ & $64(81)$ & $235(83)$ \\
\hline None & $11(6)$ & $5(6)$ & $16(6)$ \\
\hline
\end{tabular}

\section{Analysis of Strokes}

Strokes were diagnosed on average of 1.3 days (range 0-11 days) from admission. The imaging modality used to diagnose a CVA was CT in 33 cases, MRI in 20, and both in 26 patients. Almost all children (78 of 79 [99\%]) had cerebral strokes. Interarterial watershed regions, or other areas that are well known to be susceptible to hypoperfusion (see Methods), were the most common stroke morphology (73\%). Strokes involving the region supplied by the MCA, PCA, and their watershed zones were the

TABLE 2. Description of injury severity, LOS, and hospital charges for the child's initial admission.

\begin{tabular}{|c|c|c|c|}
\hline \multirow[b]{2}{*}{ Variable } & \multicolumn{2}{|c|}{ No. of Patients } & \multirow[b]{2}{*}{ Total } \\
\hline & Without CVA & With CVA & \\
\hline No. of patients & 203 & 79 & 282 \\
\hline \multicolumn{4}{|l|}{ Injury severity (\%) } \\
\hline I & $71(35)$ & 0 & $71(25)$ \\
\hline II & $105(52)$ & $35(44)$ & $140(50)$ \\
\hline III & $27(13)$ & $44(56)$ & $71(25)$ \\
\hline \multicolumn{4}{|l|}{ Hospital LOS (days) } \\
\hline Median (range) & $3(1-36)$ & $11(0-80)$ & $4(0-80)$ \\
\hline \multicolumn{4}{|c|}{ By injury severity (range) } \\
\hline I & $2(1-6)$ & NA & $2(1-6)$ \\
\hline II & $4(1-20)$ & $12(0-45)$ & $4.5(0-45)$ \\
\hline III & $8(1-36)$ & $9(1-80)$ & $8(1-80)$ \\
\hline \multicolumn{4}{|l|}{ Hospital charges (cost) } \\
\hline Median (range) & $\$ 19,900(\$ 3700-\$ 313,00)$ & $\$ 117,000(\$ 9980-\$ 882,000)$ & $\$ 31,000(\$ 3700-\$ 882,00)$ \\
\hline Total (million) & $\$ 6.6$ & $\$ 13.8$ & $\$ 20.4$ \\
\hline \multicolumn{4}{|c|}{ Median cost by injury severity (range) } \\
\hline 1 & $\$ 12,500(\$ 3,700-\$ 30,000)$ & NA & $\$ 12,500(\$ 3,700-\$ 30,000)$ \\
\hline II & $\$ 23,500(\$ 5,300-\$ 149,000)$ & $\$ 107,000(\$ 9,980-\$ 454,000)$ & $\$ 31,000(\$ 5,300-\$ 455,000)$ \\
\hline III & $\$ 69,500(\$ 32,700-\$ 314,000)$ & $\$ 133,000(\$ 25,600-\$ 882,000)$ & $\$ 99,500(\$ 25,500-\$ 882,000)$ \\
\hline
\end{tabular}

$\mathrm{NA}=$ not applicable. 


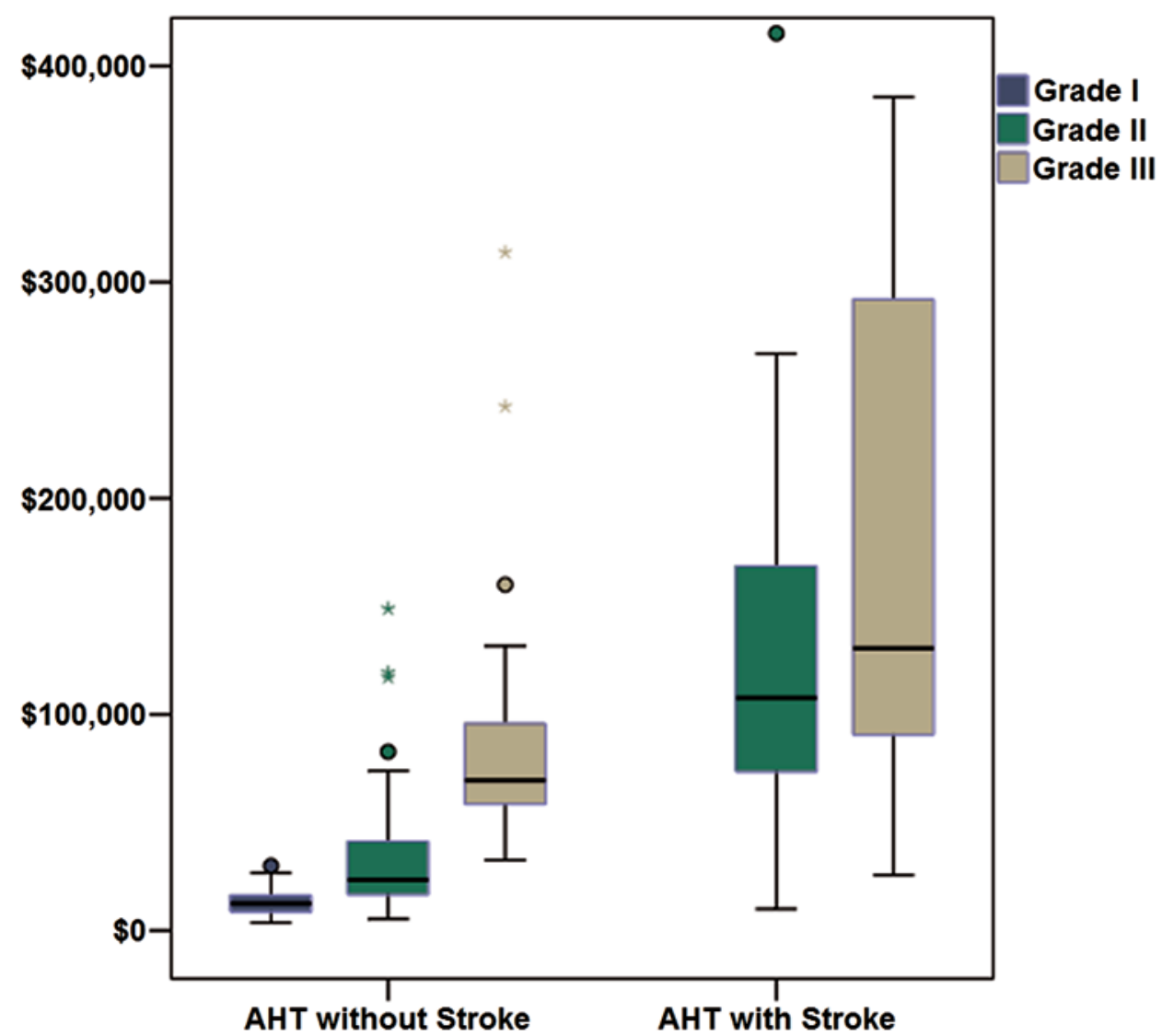

FIG. 1. Box-and-whisker diagram comparing hospital charges associated for patients with AHT alone with patients with AHT and stroke(s). This is further subdivided by grade of AHT injury. The box represents the 25th to 75th percentile, the line within the box represents the median (50th percentile), and the bars represent all values, except the outliers. Figure is available in color online only.

most commonly involved territories. The majority of patients had more than 1 vascular distribution (65 of 79 [82\%]), bilateral (62 of 79 [76\%]), and multifocal (67 of 79 [85\%]). Thirty-six patients suffered a complete hemispheric CVA and most had a SDH overlying an area of infarction.

\section{Predictors of Mortality in Children With a Stroke}

Of all the variables placed into the logistic linear regression, risk factors for death were younger age $(p=0.005$, OR 1.95) and presence of a hemispheric infarct ( $\mathrm{p}<0.001$, OR 15). The Cox and Snell R-square coefficient was 0.34, indicating that $34 \%$ of the variability in mortality could be explained by the variables included in the model.

\section{Discussion}

With the first monograph describing battered child syndrome in 1860 by French forensic physician Ambroise Tardieu, child abuse continues to plague our society. ${ }^{38}$ In fact, within the population served by our medical center, the incidence appears to be increasing. ${ }^{8}$ Of the numerous intentional injuries described in children-cranial and extracranial-stroke is well recognized, with the most catastrophic example being the holohemispheric infarct. ${ }^{21,24}$ Areas of infarction in survivors, in turn, can lead to what is termed "multicystic encephalopathy." 32
TABLE 3. Surgeries in children with Grade III injury and a stroke

\begin{tabular}{ccc}
\hline \multicolumn{1}{c}{ Description } & $\begin{array}{c}\text { Initial } \\
\text { Admission } \\
(\mathrm{n}=28)^{*}\end{array}$ & $\begin{array}{c}\text { Readmission } \\
(\mathrm{n}=13) \dagger \ddagger\end{array}$ \\
\hline Decompressive hemicraniectomy & 12 & 0 \\
\hline Bone flap replacement/cranioplasty & 1 & 5 \\
\hline Craniotomy & 2 & 3 \\
\hline Bur hole evacuation of SDH & 8 & 1 \\
\hline With drain & 8 & 1 \\
\hline Without drain & 0 & 0 \\
\hline ICP monitor & 14 & 0 \\
\hline Bolt & 12 & 0 \\
\hline EVD & 2 & 0 \\
\hline Shunt & 4 & 4 \\
\hline Subduroperitoneal & 2 & 3 \\
\hline Ventriculoperitoneal & 2 & 1 \\
\hline Transfontanelle subdural taps & 4 & 0 \\
\hline Lumbar puncture & 3 & 0 \\
\hline
\end{tabular}

$E V D=$ external ventricular drain; $I C H=$ intracranial hemorrhage; $I C P=$ intracranial pressure; $\mathrm{SDH}=$ subdural hemorrhage.

* 48 procedures were performed in 28 patients.

$\dagger 13$ procedures were performed in 13 patients.

$\ddagger$ Readmission within the first 180 days of injury. 
TABLE 4. Analysis of 79 cases of stroke

\begin{tabular}{|c|c|}
\hline Description & No. of Patients (\%) \\
\hline \multicolumn{2}{|l|}{ Imaging modality } \\
\hline CT & $33(42)$ \\
\hline MRI & $20(25)$ \\
\hline Both & $26(32)$ \\
\hline \multicolumn{2}{|l|}{ Location } \\
\hline Cerebrum & $78(99)$ \\
\hline Cerebellum & $21(27)$ \\
\hline Basal ganglia including thalamus & $12(15)$ \\
\hline Brainstem & $29(37)$ \\
\hline \multicolumn{2}{|l|}{ Morphology } \\
\hline Arterial & $18(23)$ \\
\hline Venous & $6(8)$ \\
\hline Watershed/hypoperfusion & $58(73)$ \\
\hline \multicolumn{2}{|l|}{ Vascular territory } \\
\hline MCA & $57(72)$ \\
\hline ACA & $46(58)$ \\
\hline PCA & $66(84)$ \\
\hline PICA & $12(15)$ \\
\hline AICA & $4(5)$ \\
\hline SCA & $8(10)$ \\
\hline \multicolumn{2}{|l|}{ No. of vascular distributions affected } \\
\hline 1 & $14(18)$ \\
\hline 2 & $23(29)$ \\
\hline 3 & $27(34)$ \\
\hline 4 & $7(9)$ \\
\hline$>4$ & $8(10)$ \\
\hline Bilateral & $62(78)$ \\
\hline Multifocal & $67(85)$ \\
\hline Hemispheric & $36(46)$ \\
\hline SDH overlying stroke & $68(86)$ \\
\hline
\end{tabular}

\section{Our Findings}

Our study combined demographic, clinical, radiographic, cost, and readmission data on children with and without a stroke. The first notable finding is that almost $30 \%$ of our AHT population suffered one or more stroke. There was no significant demographic difference between our two cohorts. As with our previous study, ${ }^{8}$ the majority of victims were male, African American, and publically insured, which is a reflection of the known risk factors for AHT and the ethnic and socioeconomic composition of the population served by $\mathrm{LBCH}$. Our incidence of stroke might be higher had all of our patients undergone MRI (33 of 79 [42\%] were diagnosed by CT only). While there are numerous studies that detail radiographic findings in children with NAT, very few studies have reported the overall incidence. In a 7-year period, Ghahreman et al. found "cerebral edema or ischemia" by CT or MRI in 22 of (33.8\%) 65 patients. ${ }^{23}$ Reviewing data obtained in 57 consecutive cases over a 13 -year period, Foerster et al. found that MRI had been performed in 48 patients, of whom 15 (31\%) had ischemia.
What was striking was the difference in injury severity, hospital stay, and hospital charges. More children with a stroke had a Grade III injury (56\% vs 13\%), which translated into longer median LOS (11 vs 3 days) and much higher median hospital charges ( $\$ 117,000$ vs $\$ 19,900)$. The difference in LOS and hospital charges was so significant between those children with a stroke and those without stroke among Grade II and III injuries that we believe it warranted a modification to the injury grading scale we proposed in our previous publication (Table 5).

The in-hospital mortality rate was $25 \%$ in the children with a stroke. We found that younger age and hemispheric infarct were predictors of mortality. This is in contrast to findings reported by Foster et al., who observed no association between what they call "hemispheric hypodensity" and mortality. Shein et al. found that a low initial Glasgow Coma Scale score, retinal hemorrhages, intraparenchymal hemorrhage, and cerebral edema were independently associated with mortality. ${ }^{41}$ Not surprisingly, survivors of NAT continue to require medical services after their initial hospitalization. Nearly one-third of children who suffered a stroke required readmission within the first 180 days of their injury, with half of them requiring surgery (either elective cranioplasty or shunt surgery).

The exact pathophysiology of a CVA in AHT continues to be a mystery. What is clear is that the AHT leads to a disturbance in the oxygen delivery to the brain, the degree to which is presumably variable, that then results in one or more infarction. Our study supports the notion that it is more often a global delivery deficit because the majority of our children exhibited strokes that were watershed/hypoperfusion in morphology, bilateral, multifocal, and involved more than a single vascular territory. This hypoperfusion or hypoxia (as a result of impaired respiration or ventilation) may be due to prolonged seizure(s), bradycardia or apnea, hypotension, vasospasm of the skull base vasculature, or a choking maneuver in addition to a shaking or impact mechanism. None of our patients had an identifiable vascular injury, such as a dissection, which is consistent with the current literature. This is an important distinction, as the word "stroke" should not immediately imply an underlying arterial pathology (narrowing or occlusion) in these patients. Terminology such as "hypodensity," "diffusion restriction," or "diffusion abnormality" may be better suited for this population when describing one or more infarctions.

The role of blood in the subdural space as it pertains to the development of a CVA is also not fully understoodbut likely has a role-in addition to any elevation of intracranial pressure it may cause. ${ }^{40,47}$ While strokes are commonly in the same hemisphere as a subdural hematoma (83\% of patients in our series), many children may have subdural hematomas or a mix of hematoma and hygroma without an underlying CVA..$^{21}$ Elevated intracranial pressure with brain shift and herniation is likely the cause for pure arterial infarctions, such as PCA, ACA, and even SCA, but these were present in only $23 \%$ of our patients.

\section{Study Strengths and Limitations}

Our study represents a continual retrospective cohort of patients over a period of more than 7.5 years and provides 
TABLE 5. Modified grading system for AHT

\begin{tabular}{cc}
\hline Grade & Description \\
\hline I & Skull fracture alone with or without associated craniofacial soft-tissue injury. \\
\hline Ila & Intracranial hemorrhage or cerebral edema not requiring surgical intervention. Brain infarction not seen on CT or MRI. \\
\hline Ilb & Intracranial hemorrhage or cerebral edema not requiring surgical intervention. Brain infarction present on CT or MRI. \\
\hline IIla & $\begin{array}{c}\text { Intracranial hemorrhage or cerebral edema requiring surgery or procedure; or death due to intracranial injuries. Brain } \\
\text { infarction not seen on CT or MRI. }\end{array}$ \\
\hline IIlb & $\begin{array}{c}\text { Intracranial hemorrhage or cerebral edema requiring surgery or procedure; or death due to intracranial injuries. Brain } \\
\text { infarction present on CT or MRI. }\end{array}$ \\
\hline
\end{tabular}

Modified from Boop et al.: Abusive head trauma: an epidemiological and cost analysis. J Neurosurg Pediatr 18:542-549, 2016. Copyright

American Association of Neurological Surgeons. Published with permission.

detailed demographic, clinical, surgical, radiographic, cost, and readmission data. These findings were confined to a single center, which could limit generalizability to other institutions that serve a population of different socioeconomic and ethnic makeup. As previously mentioned, not all of our patients were able to undergo an MRI, which may have falsely lowered our overall stroke rate since CT scanning may have missed smaller areas of infarction. Our study was limited to the initial hospitalization and the 180day period that followed. Long-term data evaluating cost, neurological development, disability and recovery, school performance, and psychosocial behavior are not available.

\section{Conclusions}

About $30 \%$ of children with AHT will develop one or more stroke, and these patients are more likely to require surgical intervention, greater hospital LOS, and higher hospital charges. Their mortality rate is $25 \%$, and younger age and the presence of hemispheric strokes are predictors of death. Strokes are most commonly due to a global hypoxic event as strokes in these children are commonly bilateral, multifocal, and in regions that are susceptible to hypoperfusion. A subdural hematoma on the same side as a cerebral infarct is very common. Approximately onethird of survivors will return to the hospital for neurosurgical issues, and half of these individuals will undergo surgery (planned or unplanned). The difference in health care utilization among children with a stroke and those without stroke is so profound that we have modified our original injury grading system to reflect this. ${ }^{8}$

\section{Acknowledgments}

We wish to thank Andrew J. Gienapp (Department of Medical Education, Methodist University Hospital, and Department of Neurosurgery, University of Tennessee Health Science Center, Memphis, TN) for technical and copy editing, preparation of the manuscript and figures for publication, and publication assistance with this manuscript.

\section{References}

1. Ashwal S, Wycliffe ND, Holshouser BA: Advanced neuroimaging in children with nonaccidental trauma. Dev Neurosci 32:343-360, 2010

2. Babikian T, Tong KA, Galloway NR, Freier-Randall MC, Obenaus A, Ashwal S: Diffusion-weighted imaging predicts cognition in pediatric brain injury. Pediatr Neurol 41:406412, 2009

3. Barlow KM, Gibson RJ, McPhillips M, Minns RA: Magnetic resonance imaging in acute non-accidental head injury. Acta Paediatr 88:734-740, 1999

4. Barlow KM, Thomson E, Johnson D, Minns RA: Late neurologic and cognitive sequelae of inflicted traumatic brain injury in infancy. Pediatrics 116:e174-e185, 2005

5. Biousse V, Suh DY, Newman NJ, Davis PC, Mapstone T, Lambert SR: Diffusion-weighted magnetic resonance imaging in Shaken Baby Syndrome. Am J Ophthalmol 133:249255, 2002

6. Bishop NB: Traumatic brain injury: a primer for primary care physicians. Curr Probl Pediatr Adolesc Health Care 36:318-331, 2006

7. Bonnier C, Nassogne MC, Saint-Martin C, Mesples B, Kadhim H, Sébire G: Neuroimaging of intraparenchymal lesions predicts outcome in shaken baby syndrome. Pediatrics 112:808-814, 2003

8. Boop S, Axente M, Weatherford B, Klimo P Jr: Abusive head trauma: an epidemiological and cost analysis. J Neurosurg Pediatr 18:542-549, 2016

9. Buttram SD, Garcia-Filion P, Miller J, Youssfi M, Brown $\mathrm{SD}$, Dalton HJ, et al: Computed tomography vs magnetic resonance imaging for identifying acute lesions in pediatric traumatic brain injury. Hosp Pediatr 5:79-84, 2015

10. Catherine NL, Ko JJ, Barr RG: Getting the word out: advice on crying and colic in popular parenting magazines. J Dev Behav Pediatr 29:508-511, 2008

11. Choudhary AK, Bradford R, Dias MS, Thamburaj K, Boal DK: Venous injury in abusive head trauma. Pediatr Radiol 45:1803-1813, 2015

12. Christian CW, Block R: Abusive head trauma in infants and children. Pediatrics 123:1409-1411, 2009

13. Duhaime AC: Demographics of abusive head trauma. J Neurosurg Pediatr 1:349-350, 2008

14. Duhaime AC, Bilaniuk L, Zimmerman R: The "big black brain": radiographic changes after severe inflicted head injury in infancy. J Neurotrauma 10:S59, 1993

15. Duhaime AC, Christian C, Moss E, Seidl T: Long-term outcome in infants with the shaking-impact syndrome. Pediatr Neurosurg 24:292-298, 1996

16. Duhaime AC, Christian CW, Rorke LB, Zimmerman RA: Nonaccidental head injury in infants - the "shaken-baby syndrome.” N Engl J Med 338:1822-1829, 1998

17. Duhaime AC, Gennarelli TA, Thibault LE, Bruce DA, Margulies SS, Wiser R: The shaken baby syndrome. A clinical, pathological, and biomechanical study. J Neurosurg 66:409-415, 1987

18. Finkler SA: The distinction between cost and charges. Ann Intern Med 96:102-109, 1982

19. Flom L, Fromkin J, Panigrahy A, Tyler-Kabara E, Berger RP: 
Development of a screening MRI for infants at risk for abusive head trauma. Pediatr Radiol 46:519-526, 2016

20. Foerster BR, Petrou M, Lin D, Thurnher MM, Carlson MD, Strouse PJ, et al: Neuroimaging evaluation of non-accidental head trauma with correlation to clinical outcomes: a review of 57 cases. J Pediatr 154:573-577, 2009

21. Foster KA, Recker MJ, Lee PS, Bell MJ, Tyler-Kabara EC: Factors associated with hemispheric hypodensity after subdural hematoma following abusive head trauma in children. J Neurotrauma 31:1625-1631, 2014

22. Galloway NR, Tong KA, Ashwal S, Oyoyo U, Obenaus A: Diffusion-weighted imaging improves outcome prediction in pediatric traumatic brain injury. J Neurotrauma 25:11531162,2008

23. Ghahreman A, Bhasin V, Chaseling R, Andrews B, Lang EW: Nonaccidental head injuries in children: a Sydney experience. J Neurosurg 103 (3 Suppl):213-218, 2005

24. Gilles EE, Nelson MD Jr: Cerebral complications of nonaccidental head injury in childhood. Pediatr Neurol 19:119-128, 1998

25. Hahnemann ML, Kinner S, Schweiger B, Bajanowski T, Karger B, Pfeiffer H, et al: Imaging of bridging vein thrombosis in infants with abusive head trauma: the "tadpole sign". Eur Radiol 25:299-305, 2015

26. Haviland J, Russell RI: Outcome after severe non-accidental head injury. Arch Dis Child 77:504-507, 1997

27. Jacob R, Cox M, Koral K, Greenwell C, Xi Y, Vinson L, et al: MR imaging of the cervical spine in nonaccidental trauma: a tertiary institution experience. AJNR Am J Neuroradiol [epub ahead of print], 2016

28. Jaspan T, Griffiths PD, McConachie NS, Punt JA: Neuroimaging for non-accidental head injury in childhood: a proposed protocol. Clin Radiol 58:44-53, 2003

29. Kadom N, Khademian Z, Vezina G, Shalaby-Rana E, Rice A, Hinds T: Usefulness of MRI detection of cervical spine and brain injuries in the evaluation of abusive head trauma. Pediatr Radiol 44:839-848, 2014

30. Kemp AM, Jaspan T, Griffiths J, Stoodley N, Mann MK, Tempest V, et al: Neuroimaging: what neuroradiological features distinguish abusive from non-abusive head trauma? A systematic review. Arch Dis Child 96:1103-1112, 2011

31. King WJ, MacKay M, Sirnick A: Shaken baby syndrome in Canada: clinical characteristics and outcomes of hospital cases. CMAJ 168:155-159, 2003

32. Kubat B, Bilo RA, van Rijn RR: Multicystic encephalopathy in abusive head trauma. Clin Neuropathol 33:299-307, 2014

33. Merten DF, Osborne DR, Radkowski MA, Leonidas JC: Craniocerebral trauma in the child abuse syndrome: radiological observations. Pediatr Radiol 14:272-277, 1984

34. Niederkrotenthaler T, Xu L, Parks SE, Sugerman DE: Descriptive factors of abusive head trauma in young childrenUnited States, 2000-2009. Child Abuse Negl 37:446-455, 2013

35. Nuño M, Pelissier L, Varshneya K, Adamo MA, Drazin D: Outcomes and factors associated with infant abusive head trauma in the US. J Neurosurg Pediatr 16:512-522, 2015

36. Palifka LA, Frasier LD, Metzger RR, Hedlund GL: Parenchymal brain laceration as a predictor of abusive head trauma. AJNR Am J Neuroradiol 37:163-168, 2016
37. Parks SE, Annest JL, Hill HA, Karch DL: Pediatric Abusive Head Trauma: Recommended Definitions for Public Health Surveillance and Research. Atlanta: Centers for Disease Control and Prevention, 2012, pp 5-12

38. Roche AJ, Fortin G, Labbé J, Brown J, Chadwick D: The work of Ambroise Tardieu: the first definitive description of child abuse. Child Abuse Negl 29:325-334, 2005

39. Schaefer PW, Huisman TA, Sorensen AG, Gonzalez RG, Schwamm LH: Diffusion-weighted MR imaging in closed head injury: high correlation with initial Glasgow Coma Scale score and score on modified Rankin scale at discharge. Radiology 233:58-66, 2004

40. Shaver EG, Duhaime AC, Curtis M, Gennarelli LM, Barrett $\mathrm{R}$ : Experimental acute subdural hematoma in infant piglets. Pediatr Neurosurg 25:123-129, 1996

41. Shein SL, Bell MJ, Kochanek PM, Tyler-Kabara EC, Wisniewski SR, Feldman K, et al: Risk factors for mortality in children with abusive head trauma. J Pediatr 161:716-722, 722.e1, 2012

42. Sieswerda-Hoogendoorn T, Boos S, Spivack B, Bilo RA, van Rijn RR: Abusive head trauma Part II: radiological aspects. Eur J Pediatr 171:617-623, 2012

43. Silvera VM, Danehy AR, Newton AW, Stamoulis C, Carducci C, Grant PE, et al: Retroclival collections associated with abusive head trauma in children. Pediatr Radiol 44 (Suppl 4):S621-S631, 2014

44. Suh DY, Davis PC, Hopkins KL, Fajman NN, Mapstone TB: Nonaccidental pediatric head injury: diffusion-weighted imaging findings. Neurosurgery 49:309-320, 2001

45. Tanoue K, Aida N, Matsui K: Apparent diffusion coefficient values predict outcomes of abusive head trauma. Acta Paediatr 102:805-808, 2013

46. Tung GA, Kumar M, Richardson RC, Jenny C, Brown WD: Comparison of accidental and nonaccidental traumatic head injury in children on noncontrast computed tomography. Pediatrics 118:626-633, 2006

47. Yilmazlar S, Hanci M, Oz B, Kuday C: Blood degradation products play a role in cerebral ischemia caused by acute subdural hematoma. J Neurosurg Sci 41:379-385, 1997

\section{Disclosures}

The authors report no conflict of interest concerning the materials or methods used in this study or the findings specified in this paper.

\section{Author Contributions}

Conception and design: Klimo. Acquisition of data: Khan, Fraser, Nguyen, Moore, Boop, Vaughn. Analysis and interpretation of data: Klimo, Khan. Drafting the article: Klimo, Khan. Critically revising the article: all authors. Reviewed submitted version of manuscript: Klimo. Approved the final version of the manuscript on behalf of all authors: Klimo. Statistical analysis: Khan. Study supervision: Klimo.

\section{Correspondence}

Paul Klimo, Semmes Murphey Clinic, 6325 Humphreys Blvd., Memphis, TN 38120. email: pklimo@semmes-murphey.com. 